\title{
Healthcare in an interdependent world
}

\author{
Fiona Godlee editor in chief
}

The BMJ

Should the United Kingdom stay in the European Union or should it go, and how would a decision to leave ("Brexit") after the referendum affect the NHS and doctors' working lives? John Appleby kicks off The BMJ's coverage of the issue with his data briefing this week (doi:10.1136/bmj.i2328). The problem for anyone wanting to make an evidence based decision in the referendum, he says, is the lack of a comprehensive and reliable analysis that weighs up the pros and cons.

We hope to help. Starting next week, a series of articles will look at how Brexit would affect key aspects of health and healthcare: drug availability and regulation, public health, the rights of health professionals, cross border movement of doctors and patients, and finally the funding and business model of the NHS itself.

One person in no doubt about the threat that Brexit poses to the NHS is Martin McKee (doi:10.1136/bmj.i2489). The European Parliament has listened to concerns about international trade agreements, many of which have been taken on board, he says, and so these can no longer justify calls to leave. In light of this, McKee asks us who is more likely to protect the NHS: a parliament in Europe that has made clear its commitment to protect public services or those currently campaigning for Brexit? He reminds us that these include Daniel Hannan MEP, who once described the NHS as a 60 year "mistake."
Not a mistake but a fiction, says Richard Smith in a BMJ blog (http://bit.ly/1UvUgLZ), made up simply of three values: universal healthcare coverage; provision by need rather than ability to pay; and equal quality of care for all. We haven't fully realised any of them, he says, and our approach must urgently evolve. "To keep the NHS alive we need to move rapidly from a service dominated by hospitals, doctors, disease, death denial, and drugs and surgery to one that is more about community services, teams including patients, life enhancement, and a wider range of interventions, including urban redesign, changes in food supply, and much more."

This isn't going to be easy, but at least the UK has a head start. Other countries are just embarking on the journey to universal coverage, and good information to guide them is lacking. Merely increasing access to poor quality health systems could do more harm than good, says our editorial (doi:10.1136/bmj.i2216), not least in diverting resources from public health and education.

To fill this knowledge gap The BMJ has teamed up with Harvard Global Health Institute to encourage the building of a global evidence base for effective universal coverage. "The world has increasingly come to realise that we are interdependent and that a poor performing health system in one place is a threat to us all." 